\title{
Angioleiomyoma in the posterior knee: a case report and literature review
}

\author{
Raymond KLUMPP ${ }^{1}$, Riccardo COMPAGNONI ${ }^{1}$, Gianluigi PATELLI ${ }^{1}$, Carlo Lauro TREVISAN ${ }^{1}$ \\ 1 - ASST Bergamo Est - Ospedale Bolognini - Seriate
}

Keywords: Angioleiomyoma; Knee; Magnetic resonance

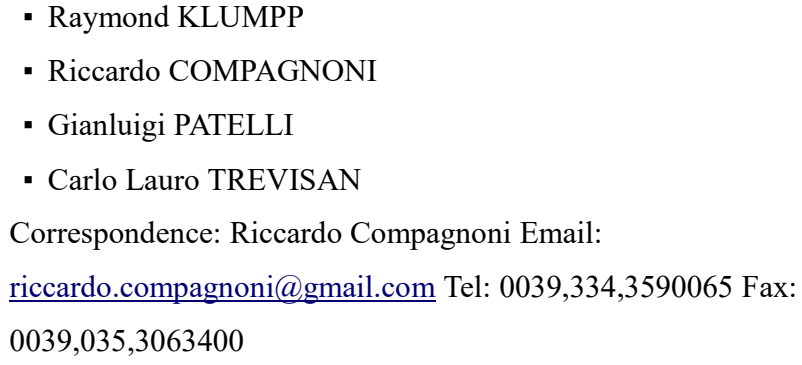

The study was carried out in ASST Bergamo Est - Ospedale Bolognini - Seriate - Italy

No benefits in any form have been received or will be received from a commercial party related directly or indirectly to the subject of this article. 
Angioleiomyoma is defined as a leiomyoma of the blood vessel, a benign neoplasm originating from the "tunica media" of the vessel walls [1]. Its histological appearance consisting of smooth muscle and prominent blood vessels is characteristic $[2,3,4,5]$. The incidence of angioleiomyoma is estimated about $5 \%$ among all soft tissue tumors with the lower limbs being most commonly affected [2]. However, the presence of the neoplasm at the knee joint is very rare and only few cases are reported in the literature $[6,7,8,9,10,11,12]$. Its clinical appearance seems more common in middle-aged people with females being affected almost twice as often $[2,8,13,14,15,16]$. Localized pain in the subcutaneous region is a typical clinical symptom $[2,17]$, reason why in the past it was also named improperly as "tuberculum dolorosum" while believing that the neoplasm was a cutaneous leiomyoma $[18,19]$. Being the angioleiomyoma a rare clinical entity and due to the lack of awareness among orthopedic surgeons, making diagnosis before surgery is uncommon [20]. Indeed, it may happen that the patient is treated repeatedly by conservative and also surgical means before their problem is solved, especially if the neoplasm is situated in proximity to the knee joint $[8,21,22]$, a district frequently treated by physicians for other common pathologies like meniscus or cartilage disease, as occurred in our clinical case. The authors present a case of angioleiomyoma situated in the posterior knee. To their knowledge, no other such cases have been reported in the literature.

\section{Case report}

A 47-year-old caucasian woman presented in 2011 with recurrent stabbing pain on the lateral aspect of her right knee. She had no history of trauma. She was in good health and wasn't on any regular medication. Neither did she take hormonal contraceptives in the past. The onset of pain was sudden and intense with irradiation in both proximal and distal direction along the lateral side of the limb that lasted for about 1 minute, this occurred about once or twice a day on a regular basis over the years. The patient kept a meticulous diary of her disease history reporting specific activities and events that triggered pain, the frequency of pain events and subjective therapeutical success of treatments (Table 1). She started having those symptoms for no apparent reason since 2005. The same year Ultrasonography and Doppler-sonography were executed being both normal and X-rays of the knee were taken showing slight narrowing of the medial joint line. A MRI of the knee in 2006 reported moderate troclear dysplasia with excessive lateral pressure of the patella. In 
2008 she was treated by diagnostic arthroscopy and transposition of the tibial tuberosity with no benefit on her symptoms. At our first clinical evaluation of the knee in 2011 there were no signs of meniscal pathology nor instability. Indeed, the pain could be triggered by digital pressure just posterior to the fibular head and seemed to be of neuropathic origin being described by the patient as an electric shock migrating along the limb. A new MRI of the knee was obtained in 2011 which seemed substantially normal. The same year electromyography of the lower limbs was performed showing asymmetry of the amplitude of sensitive action potential of the superficial fibular nerve. A MRI of the spine showed some minor lumbar protrusions in absence of root compression. Based on the clinical suspicion of an entrapment of the common fibular nerve at its bifurcation a surgical exploration was proposed and accepted by the patient in 2012. However after surgery the symptoms persisted. In order to rule out a subtle nerve root compression situated in the lumbar spine that could explain the symptoms a MRI in orthostatic position was performed in 2013 that confirmed the presence of minor lumbar protrusions but in absence of root compression. During her illness the patient tried different kinds of treatment (oral administration of alpha lipoid acid for 6 months as well as pregabalin $225 \mathrm{mg}$ /day for 2 months, physiotherapy, osteopathy) without any changes in symptoms. Five consecutive sessions of acupuncture as well as a 15 day treatment with clay packs seemed to decrease the pain intensity and frequency for a short period of time. In 2014 for the first time an ultrasonography localized at the trigger point showed a solid ovalar vascular formation of 1 centimeter in diameter situated on the posterior aspect of the external femoral condyle in proximity to the joint capsule, confirmed by a new MRI of the knee (Figure 1,2). In fact, when this MRI was compared to the previous MRI of 2011, retrospectively the neoplasm was already present, but wasn't diagnosed back then by both radiologist and treating surgeon. Surgical excision of the tumor mass measuring $1 \mathrm{~cm}$ in diameter relieved symptoms immediately and permanently (Figure 3,4). Histology evidenced the presence of a solid-type angioleiomyoma.

\section{Discussion}

Leiomyoma of the soft tissues is a benign neoplasm deriving from smooth muscle cells. It can be divided into 3 groups: superficial leiomyoma, vascular leiomyoma and deep leiomyoma, with the angioleiomyoma being a variant that typically occurs as a painful subcutaneous nodule [18]. Its presence in the subfascial-intramuscolar region is 
uncommon though some isolated cases of deeply situated angioleiomyoma involving the sciatic and median nerve have been reported [23,24]. Angioleiomyoma is considered by the World Health Organization as a distinct tumoral entity forming a morphological continuum with myopericytoma and myofibroma [25].

An Angioleiomyoma typically presents as a small, slow-growing mass in the cutaneous and subcutaneous tissue that becomes painful over time and affects the lower extremity in $70 \%$ of cases in subjects between 40 and 70 years of age with women being affected almost twice as often [2]. The size of the tumor is less than 2 centimeters in diameter in more than $80 \%$ of cases [2], whereas there seems to be no correlation between size of the tumor and presence of pain [15]. All of these clinical features of angioleiomyoma are presented in our clinical case with the exception of the location of the tumor that was situated close to the knee joint capsule.

Usually patients have clinical symptoms such as pain (present in 50-70\% of lesions) [2] and tenderness for many years before seeking medical advice [2,3]. Pain is typically described as paroxysmal and sharp or pinching. Climate change and light touch seem to trigger the pain that is experienced more frequently in the lower limb lesions [3]. Physical rest seems to alleviate symptoms [15]. However, the etiology of pain remains unclear with hypothesis ranging from pain originating from smooth muscle contraction, to local ischemia due to blood vessel spasm and irritation of nerves in proximity $[19,26]$. In our clinical case pain was mainly reported while walking, while getting up from a sitting position and during sleep.

The etiology of Angioleiomyoma is reported to be multifactorial depending on genetics, trauma, pregnancy, estrogenic therapies, venous stasis and vascular malformation deriving from arteriovenous anastomoses $[5,27,28,29]$. Other authors hypothized that these tumors are hamartomas [2] or originate from smooth muscle proliferation in a hemangioma [3].

There are no specific imaging techniques available to make diagnosis of angioleiomyoma. On ultrasound its margins are well defined with a homogenous structure. MRI findings are relatively non-specific with the lesion showing hyperintense signal on T2- weighted images and hypointense signal in T1 [30]. The vascular component of the lesion can be evidenced by Gadolinium enhancement. Two out of three MRIs of this patient did not report the angioleiomyoma and transposition of the tibial tuberosity as well as an exploration of the common fibular nerve were performed unnecessarily. However, when comparing the last MRI showing the neoplasm with the earlier one the neoplasm was already visible retrospectively, but not diagnosed. This shows how both orthopedic surgeons and 
radiologists when treating the knee have a strong bias towards common pathologies they encounter everyday. Whereas clinics and imaging techniques can easily miss to diagnose the presence of angioleiomyoma as happened in our case, its histological appearance is characteristic with the lesion being composed of bundles of smooth muscle and vascular channels in absence of cytological atypia and mitotic activity [2,31]. Morimoto [31] divided these tumors in 3 histological groups: 1) Solid tumors which are most common and typically painful, made of densely compacted smooth muscle with slit-like vascular channels [31]; 2) venous tumors that are made of thick vascular walls with intravascular smooth muscle; 3 ) cavernous tumors that show dilated vascular channels with smooth muscle thickening limited to the vessel wall. Both venous and cavernous tumors are typically painless [31].

In persistent knee pain that remains unexplained otherwise, clinicians should be aware of atypical locations of angioleiomyoma as a rare source of pain not responding to conventional therapies and where surgical excision only of the tumor can be considered as the definite cure.

\section{Literature}

1. Chen YA, Chuang WY, Hsueh S, Chan KC. Solitary nodule on the auricle. Int J Dermatol 2012; 51: 1427-8.

2. Hachisuga $\mathrm{T}$, Hashimoto $\mathrm{H}$, Enjoji M: Angioleiomyoma: clinicopathologic reappraisal of 562 cases. Cancer 1984, 51:126-130.

3. Duhig JT, Ayer JP, Vascular leiomyoma. A study of sixty one cases, Arch. Pathol.68 (1959) 424-430.

4. Magner D, Hill DP, Encapsulated angiomyoma of the skin and subcutaneoustissues, Am. J. Clin. Pathol. 35 (1961) 137-141.

5. Matsuyama A, M. Hisaoka M, Hashimoto $H$, Angioleiomyoma: a clinicopathologicand immunohistochemical reappraisal with special reference to the correlationwith myopericytoma, Hum. Pathol. 38 (2007) 645-651.

6. Dicaprio MR, JokI P: Vascular leiomyoma presenting as medial joint line pain of the knee. Arthroscopy 2003, 19:E24.

7. Thienpont E, Geens S, Nelen G: Angioleiomyoma of the knee. A case report. Acta Orthop Belg 2002, 68:76-78.

8. Okahashi K, Sugimoto K, Iwai M, Oshima M, Takakura Y: Intraarticular angioleiomyoma of the knee: a case report. Knee 2006, 13:330-332.

9. Gassel F, Sommer T, Meybehm M, Schmitt O: A case of an unusual space occupying lesion in the knee joint. Radiologe 1999, 39:703-705.

10. Murty AN, Ireland J: Angiomyoma of the patellar fat pad. Knee 2000, 7:253-254.

11. Fukawa T, Akatsu Y, Sasho T.Intra-articular angioleiomyoma of the knee with an atypical finding on gadolinium-enhanced magnetic resonance imaging: a case report. J Med Case Rep. 2014 Jul 1;8:238. 
12. Gulati MS, Kapoor A, Maheshwari J. Angiomyoma of the kneejoint: value of magnetic resonance imaging. Australas Radiol 1999;43: 353-4.

13. Kinoshita T, Ishii K, Abe Y, Naganuma H. Angiomyoma of the lower extremity: MR findings. Skeletal Radiol 1997; 26: 443-445.

14. Okahashi K, Sugimoto K, Iwai M, Tanaka M, Fujisawa Y, Takakura Y.Intra-articular synovial hemangioma; a rare cause of knee pain and swelling. Arch Orthop Trauma Surg 2004;124:571-3.

15. Freedman AM, Meland NB Angioleiomyomas of the extremities: report of a case and review of the Mayo Clinic experience. Plast Reconstr Surg 1989 83(2):328-331.

16. Hanft J R, Carbonell J A,Do H Q Angioleiomyoma of the lower extremity. J.Am Podiatr Med Assoc 1997 87(8):388-391.

17. Stout AP: Solitary cutaneous and subcutaneous leiomyoma. Am J Cancer 1937, 29:435-469.

18. Enzinger $F$ M,Weiss $S W$ Benign tumors of smooth muscle. In: Enzinger $F M$, Weiss $S$ W (Ed) Soft tissue tumors.C V Mosby, St Louis,Washington D C,Toronto, 1995 S 383401.

19. Hasegawa T, Seki K,Yang P, Hirose T, Hizawa K Mechanism of pain and cytoskeletal properties in angioleiomyomas: an immunohistochemical study. Pathol Int 1994 44(1): 66- 72.

20.Hamoui M, Largey A, Ali M, Fauré P, Roche O, Hebrard W, Canovas F.Angioleiomyoma in the ankle mimicking tarsal tunnel syndrome: a case report and review of the literature.J Foot Ankle Surg. 2010 Jul-Aug;49(4):39.

21. Al-Jabri T, Garg S, Rao S. A rare case of angioleiomyoma of the knee: a case report. Cases J. 2009 Aug 25;2:7885

22. Gassel F, Sommer T, Meybehm M, Schmitt O. A case of unusual space-occupying lesion in the knee joint. Radiologe. 1999 Aug;39(8):703-5.

23. Piers W, Terrono AL, Hayek J, Millender LH. Angiomyoma (vascular leiomyoma) of the median nerve. J Hand Surg 1995 July 12:285-286

24. Scott WW, Hruban RH, Campbell JN, et al. Angioleiomyoma involving the sciatic nerve: CT demonstration. Clin Imaging 1993 17:260-262

25. Fletcher CD, Unni KK, Mertens F. World Health Organization Classification of Tumours: Pathology and Genetics of Tumours of Soft Tissue and Bone, 2002 IARC Press. Lyon

26. Pastore RL, laniro G. Cutaneous angioleiomyoma. J Am Podiatr Med Assoc 1999 89:145-147

27. Jougla E, Grolleau JL, Chavoin JP. Angioleiomyoma of the hand: a post traumatic tumor? Chir Main 1999 18:216-219

28. Ekestrom S. A comparison between glomus tumour and angioleiomyoma. Acta Pathol Microbiol Scand 1950 27:86-93

29. Tsoutsouris G. Vascular leiomyoma. J Foot Surg 1982 21:37-40

30. Hwang JW, Ahn JM, Kang HS, Suh JS, Kim SM, Seo JW. Vascular leiomyoma of an extremity: MR imaging-pathology correlation. AJR Am J Roentgenol 1998 171:981985

31. Morimoto N. Angiomyoma: a clinicopathologic study. Med J Kagoshima U. 1973 $24: 663-683$.

Table 1: Number of pain recurrences observed by the patient from 2009 to 2013 related to specific activity

Figure 1: T1 weighted axial MRI shows mass of $1 \mathrm{~cm}$ in diameter (arrow) adjacent to external femoral condyle in the posterior part of the knee joint. The mass is homogenous and isointense to muscle. 
Figure 2: T1 weighted axial MRI post-contrast image showing avid, homogenous enhancement of the mass (arrow).

Figure 3: Clinical appearance of the tumor (circle).

Figure 4: The mass after resection. 